\title{
6
}

\section{SEARCHING FOR A UNICORN}

\section{Fake news and electoral behaviour}

\author{
Luigi Curini and Eugenio Pizzimenti
}

\section{Introduction}

Recent evidence shows that: (1) elections across the globe have been characterised by a swing towards populism - from the 2016 US presidential elections to the 2018 Italian parliamentary elections; (2) populist politicians appear to rely more on their online communication on fake news than any political counterpart. Putting these two facts together, a number of commentators have suggested that the spread of fake news is somehow responsible for affecting electoral results (for examples, see Parkinson 2016; Read 2016; Hall Jamieson 2018). Still, it remains unclear if we are witnessing a causal relationship between two distinct phenomena or merely a temporal correlation that does not imply any causation. In fact, while numerous studies analyse different types of fake news campaigning, including their relative spread, their impact on the public remains an open question (Guess et al. 2020b). Our aim in this chapter is to give a critical review of the current literature, by focusing on a specific issue: can the exposure to false news actually affect people's attitudes and behaviour, and especially voting?

\section{A definition of fake news}

Today's fake news furore should be evaluated against the backdrop of long-standing political and commercial efforts to persuade and influence citizens through propaganda and political marketing (Bakir and McStay 2018). Fake news in some form has in other words long been with us (Pennycook and Rand 2019).

However, fake news seems to have gained an unprecedented level of prominence through the rise of social media. Thanks to some distinguishing features characterising the latter (low barriers to entry and reliance on user-generated content), 
the digital media ecology has in fact proliferated, democratized, and intensified the scale of this phenomenon (Allcott and Gentzkow 2017).

Two main motivations appear as the main engine for producing fake news. The first one is pecuniary: there is a growing number of people that financially capitalise on algorithms used by social media platforms and Internet search engines. Fake news articles that go viral can in fact draw significant advertising revenue or increase the value of one's own domain. The second motivation is ideological. Some fake news providers seek to advance politicians they favour. Regardless of the reason, we define fake news as either wholly false or containing deliberately misleading elements incorporated within its content or context (Rampersad and Turki 2020). That is, we intend fake news as intentionally fabricated information characterised by its politically charged content.

\section{Understanding the causal path}

To understand the possible causal linkage between fake news and voting, we need to better understand at least three aspects that are directly interrelated among themselves: the voting determinants, the psychological reasons behind consuming news, and the role of campaigning in affecting voting. As we will see, reviewing such aspects allow us to develop our expectations linking fake news with voting decisions.

\section{The voting determinants}

First, we need to develop a manageable map to orient readers on the steep terrain of the determinants of voting behaviours: this preliminary step will allow us to assess the (potential) weight of fake news and to place their (eventual) impact among the classical factors raised by the literature.

Voting behaviour is a core topic in contemporary Political Science. The detection and the study of the determinants behind people's electoral attitudes and voting choices gave birth to a vast literature, which is virtually impossible to summarise in this contribution (Fisher et al. 2017). However, to a merely heuristic aim it is possible to classify the classical theories of voting into three main approaches: (1) Sociological; (2) Psychological; (3) Rational Choice. According to the Sociological Approach (SA) - whose main pillar rests on the classic book by Lazarsfeld, Berelson, and Gaudet (1944) - voting behaviour is deeply entrenched in people's belonging to social groups. From this perspective, the sociographic properties of individuals (such as religion, race, gender, generation, occupation, class, geographical location) have an impact in orienting and stabilising, in time, their electoral preferences. Also the Psychological Approach (PA) emphasises the role played by individuals' characteristics - in particular: childhood, social background, and adult socialisation - in determining their party identification (Campbell et al 1960), which is considered the main cognitive map through which people frame politics and cast their vote accordingly. Finally, the Rational Choice Approach (RCA) builds 
on the assumptions of methodological individualism and on an economic theory of democracy (Downs 1957). Individuals are expected to behave rationally: once translated into the study of voting behaviour, this implies that citizens choose candidates/parties like consumers choose commercial products, by selecting the one whose policies best fit their preferences.

As this brief and incomplete introduction to voting behaviour theories should have suggested, there is no single way to address the puzzle of voting determinants, which proves more counter-intuitive than commonly expected. To deal with such a complicated issue, we opt to resort to the bi-dimensional approach elaborated by Rokkan (1970) and refined by Bellucci and Whiteley (2005). This analytical framework considers two different dimensions: a Macro-Micro dimension for the study of the characteristics of the political system on the one hand, and those of the voters on the other; and a Temporal dimension along which it is possible to distinguish between Distant and Contextual processes/factors that impact on voting behaviour (see also Bellucci and Segatti 2010).

By combining these two dimensions, we obtain four different quadrants within which it is possible to place the most recurring factors that impact on voters' final decision (at the centre of Figure 6.1). The quadrants placed on the left refer to the long-term determinants of voting behaviour. In the left-upper quadrant (MacroDistant) we find the main characteristics of the political system: the structure of socio-political cleavages, the format and mechanics of the party system, the

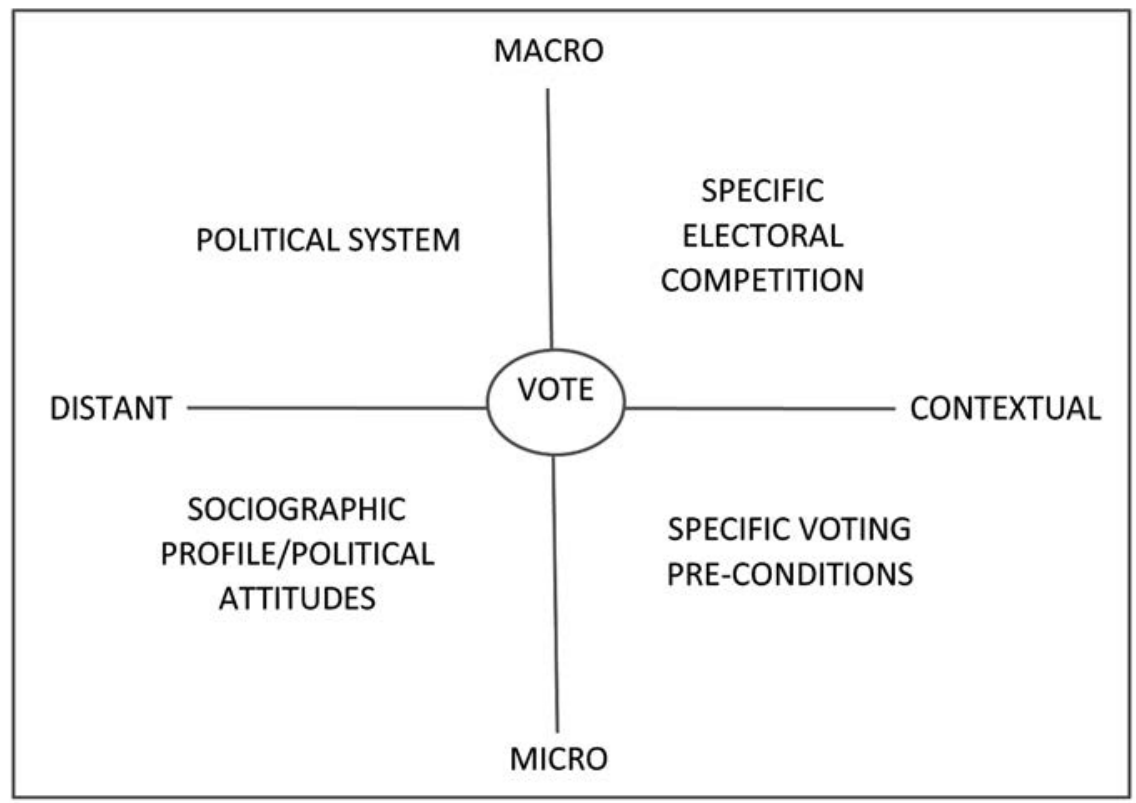

FIGURE 6.1 The analytical framework 
'rules of the game' of the political-institutional arenas, etc. These determinants are exogenous, as they represent the set of systemic constraints and opportunities that bind voters' choices. In the left-lower quadrant (Micro-Distant), the sociographic properties, the social position, the moral and political values, and the political predispositions of the individuals are included. Here we find those social/economic/ religious characteristics that are supposed to have an impact on voters' political attitudes. On the right side of the figure, the quadrants contain the contextual factors that shape a specific election and the related individual's voting decision. In the upper quadrant (Macro-Contextual), the main determinants of voting refer to the specificities of the electoral competition: the state of the economy, the patterns of parties' alignment/strategies, the most debated political themes and policy issues, the role of the political leaders during the electoral campaign, the prevailing campaigning style, etc. In this respect, voters are expected to be driven also by their own evaluations about these aspects, such as the quality of the political class, the representativeness/cohesion of parties, the performances of the outgoing government, as well as by their expectations about the future and the reliability of the debated issues. Finally, in the lower quadrant (Micro-Contextual) we find a number of individual behaviours (exposure to campaigning, social interactions) and cognitive processes at the basis of a specific voting decision. Different voters adopt different decision-making heuristics through which they frame the political messages they are exposed to, according to their emotional involvement. In this respect, the role of mass-media - as well as that of other intermediation agencies, whether collective or individual (Gunther, Montero, and Puhle 2007) - is crucial. This does not mean that other factors - such as the kind of campaigning exposure, the informal debates within the circle of relatives, friends, and colleagues - are irrelevant; on the contrary, they constitute powerful filters between political news (whether fake or not) and voters.

As we will discuss more in depth in the following sections, the recent debate on the impact of fake news on voting behaviour tends to emphasise the relevance of the determinants placed on the right side of the figure, while overlooking the others. In particular, the underlying idea that peoples' votes are largely conditioned by the contextual information they gather during each specific electoral campaign seems to be consistent with the hypothesis of the 'individualisation' of voting (Dalton 1996). According to this interpretation, as far as traditional social pillars and partisan identifications have progressively evaporated, citizens tend to adopt personal decision-making schemes based on their own assessments and perceptions of the political environment. No longer determined by traditional social/political identities (which represented powerful constraints in orienting voting decisions), voters are now considered free to select the information that best fits with their individual preferences and to vote accordingly. If this is the case, voters will be more 'contestable' by competing parties and, in general, more willing to change their preferences depending on the contextual characteristics of the electoral campaign. Within this scenario, the weight of the fake news seems to be crucial, as deliberately false information that circulates during the electoral campaign is supposed 
to produce relevant impacts on voters, whose social and political background is considered a sort of tabula rasa.

However, neither the socially determined nor the hyper-individualised model of voting are satisfactory. In fact, if it seems undisputable that the de-freezing of the long-standing socio-economic-cultural cleavages (Dalton 1996), the decline of the traditional party organisational models (Katz and Mair 1995; 2009), the parallel erosion of the traditional social pillars (Dalton and Wattenberg 2002), as well as the information technology revolution (Ward and Gibson 2009) have contributed to the individualisation of political participation, it does not necessarily follow that contemporary voters are completely deprived of any social identity and/or that they are insensitive to the influences of the wider groups they still belong to. If voters were completely individualised and impressionable by contextual factors we should register exorbitant levels of volatility at every election, everywhere, which is not the case in liberal democracies. Thus, as (substantial) stability continues to prevail, it seems plausible that voters' choice is still affected by their socially constructed and rather homogeneous social networks (Dalton 1996), whose boundaries do not vary dramatically over time.

\section{The psychological reasons behind consuming a news}

Rather than confining the debate on voting determinants to the clash between socially determined and individualised voters, we probably should build our assumptions on a model of voters' behaviour that stands "in between: for sure more strong-willed and strategic in choosing his/her affiliations, but still identified and socially situated" (Corbetta and Cavazza 2009: 371, our translation). On this basis, it is possible to elaborate an analytical framework on the relevance of fake news that eschews the widespread (deterministic) conventional wisdom about its impact. First, we need to examine whether exposure to fake news actually affects voting behavior or if it only reinforces predetermined political beliefs. To this aim we will focus on how ordinary citizens experience misinformation on social media platforms.

That sizable populations reading fake news on social media doesn't, in fact, necessarily mean that such messages influenced public attitudes. The concept of 'selective exposure' is enlightening in this respect. Research shows that people tend to prefer congenial information, including political news, when given the choice (Iyengar and Hahn 2009; Iyengar et al. 2008). Why does it happen? Because selective exposure enables people to defend their attitudes, beliefs, and behaviours by avoiding information likely to challenge them and seeking information likely to support them (Hart et al. 2009). Moreover, such 'defense' motivation is strengthened by individuals' commitment to such pre-existing attitude, belief, or behaviour (Kiesler 1971). This creates a linkage with the world of politics. In contrast to other topics, those individuals with strong political leanings may in fact be particularly likely to engage in selective exposure because their political beliefs are accessible and personally relevant (Hart et al. 2009). Politics, on the 
other side, often yields an affective response, and this is another factor that has been shown to matter to inspire selective exposure (Stroud 2008).

Today, it is moreover far easier engaging in selective exposure, i.e. in the selection of media sharing one's political predispositions, compared to times past (Stroud 2008). The existence of social media has, of course, just further strengthened this dynamic, not only on a quantitative but also on a qualitative basis. In particular, the human confirmation bias discussed above is favoured by the algorithm employed by social networks, which reinforces the creation of 'filter bubbles' where users are subjected to a limited exposure to, and lack of engagement with, different ideas and other people's viewpoints (Bessi et al. 2016; Sunstein 2001). ${ }^{1}$

\section{The role of campaigning in affecting voting}

The previous two sections should warn us about the complex mixture between consolidated attitudes and contextual factors in orienting peoples' behaviour. Among the latter, the role of political advertising deserves specific attention. Research suggests two broad reasons why campaign advertising might have effects on voters' choices (see Kalla and Broockman 2018): (1) by providing voters new arguments and/or (2) by heightening the salience of existing arguments. Still, there are reasons to take both aspects with care.

When it comes to providing voters with new arguments and information, by the time election day arrives, voters are likely to have already absorbed all the arguments and information they care to retain from the media and other sources beyond the political campaigns themselves (Gelman and King 1993). This is not to say that voters will know all the relevant information campaigns could provide them, but that they are likely to have been exposed to all this information and that they will have chosen to retain nearly all they care to (Kalla and Broockman 2018). In such an environment, it may be difficult for campaigns to change voters' minds by informing them about a party's positions, as voters are likely to agree with their party on any issues on which they have opinions in the first place (Berinsky 2009; Lauderdale 2016). Accordingly, there are few considerations campaigns can provide that would lead voters to abandon their party, in particular as election day is approaching (Kalla and Broockman 2018).

What about the possibility for a campaign to make certain considerations more salient as people decide what they think (Zaller 1992)? The salience-raising effects of communication diminish in the presence of clear cues (Druckman, Peterson, and Slothuus 2013) and when individuals are exposed to competing arguments and information (Druckman 2004). This is, however, the typical situation we meet in general elections wherein a partisan perspective makes generally other frames irrelevant to many voters.

In this sense, what a campaign typically does - providing information voters are already being exposed to and attempting to increase the salience of this information is very unlikely to lead voters to cross partisan lines. And, in fact, Kalla and Broockman (2018) convincingly show in their meta-analysis that campaigns have "minimal 
effects;" actually an effect that is not statistically different from zero. Field experiments testing the effects of online ads on political candidates and issues have also found such null effects (Nyhan 2018). ${ }^{2}$ In sum, such findings offer an important caveat to the widespread notion that people can easily manipulate citizens' political choices. By building on the three sections discussed, we can advance two main expectations:

E1) people will tend to consume the news that confirms their partisan ideas. This also should happen within social media, and, most notably, with respect to fake news;

E2) precisely for this, the impact of fake news on voting choice will be negligible.

These considerations bring us to the review of the main findings of the literature on fake news and voting.

\section{Much ado for nothing? Fake news and empirical evidence}

\section{Spreading and consumption of fake news}

Many statistics have been produced about how many times fake news was shared on Facebook or Twitter. These statistics, however, should be taken with care. First, they obscure the fact that the content being shared may not reach many voters (most people are not, for example, on Twitter and consume relatively little political news). Second, and most important, they do not adopt a relative framework, i.e., they do not consider how much these numbers mean when compared to the statistics related to the consumption of more typical mainstream news. Our review of some of the most quoted works with respect to the 'consumption' of fake news on social media shows results that are quite consistent among themselves in their conclusions, irrespective of the specific social media platform considered. ${ }^{3}$

Let's start with Twitter. Vosoughi, Roy, and Aral (2018) have studied the spread of false stories on this platform between 2006 and 2017 by following 126,000 distinct stories covering different topics. They show that these stories were tweeted and retweeted over 4.5 million times by three million people. Among these stories, those that were false diffused significantly faster, more broadly (to a larger number of users), and deeper (with a larger number of re-shares) than those that were true. The difference between the speed and the width of spreading false vs. true stories was particularly pronounced for political news. The authors suggest that the degree of novelty (higher for false news) and the extent to which the news is emotionally charged (also higher for false news) may be responsible for why Twitter users retweet fakes more.

In a related study, Tömberg (2018) models fake news as a complex contagion highlighting the role played by the echo chamber effect. He uses a metaphor in this respect: if we think of the viral spread of fake news in a social network as akin to a wildfire, an echo chamber has the same effect as a dry pile of tinder in the forest; it provides the fuel for an initial small flame that can spread to larger sticks, 
branches, trees, to finally engulf the forest. In other words, fake news spreads easier in networks where there is a presence of an echo chamber. This 'trigger' that helps us to explain why fake news spreads fast, however, is also the key to understanding who is reading this type of news.

Grinberg et al. (2019), for example, studied the exposure of Twitter users to false news during the 2016 US presidential election. They found that false political stories constituted a significant share of all news consumption (about 6\%) on Twitter. For the average Twitter user, however, content from fake news sources constituted only $1.2 \%$ of political exposures. Finally, the circulation of false news was highly concentrated, with $1 \%$ of all users exposed to about $80 \%$ of false news exposure. The retweeting of false news was even more concentrated, with about $0.1 \%$ of all users responsible for $80 \%$ of the retweets of fake political stories. Individuals most likely to engage with fake news sources were conservative leaning and highly engaged with political news. Moreover, despite the significant presence of false stories on Twitter, for people across the political spectrum, most political news exposure still came from mainstream media outlets.

A similar story appears if we focus on a study that analyses the interaction with Russian Internet Research Agency (IRA) accounts on Twitter, that have been considered as one of the major sources of fake news during the 2016 US presidential elections (Hall Jamieson 2018). Twitter reported that 1.4 million of its 69 million monthly active users had interacted with IRA accounts in early 2018, or approximately $2 \%$. In their study Baila et al. (2020) show the vast majority (80\%) of active partisan Twitter users did not interact with any IRA account. And for those who did, these interactions represented a minuscule share of their Twitter activity - on average, just $0.1 \%$ of their liking, mentioning, and retweeting on Twitter. The trait that turned out to be the best predictor of interaction with Russian trolls on Twitter was, by far, the strength of a user's pre-existing echo chamber. That is, Twitter users who followed political figures almost entirely from their own party were the ones most likely to engage with IRA agents on the platform.

Let's turn now to Facebook. Guess, Nagler, and Tucker (2019) studied the characteristics of the sharers of false news on Facebook during the 2016 US presidential election campaign. They merged survey data with respondents' Facebook profiles to measure sharing activity. First and foremost, they found that sharing this content was a relatively rare activity. The vast majority of Facebook users in their data did not share any articles from fake news domains in 2016, and this is not because people generally do not share links. While $3.4 \%$ of respondents included in the authors' data shared 10 or fewer links of any kind, 310 (26.1\%) respondents shared 10 to 100 links during the period of data collection, and 729 (61.3\%) respondents shared 100 to 1000 links. On the contrary, over $90 \%$ of the respondents in this study shared no stories from fake news domains. Moreover, and once again, the sharing activities were partisan. Indeed, the authors find evidence that the most conservative users were more likely to share this content.

If we now turn on fake news consumption, Guess, Nagler and Tucker (2019) find that approximately one in four Americans visited a fake news website (27.4\%) 
during the final weeks of the 2016 election campaign. Fake news has been defined in this research as recently created sites that frequently published false or misleading claims that overwhelmingly favour one of the presidential candidates in the weeks before the 2016 election. The previous percentage seems impressive, but these visits overall made up only about $2 \%$ of the information people consumed from websites focussing on hard news topics. The consumption was disproportionately observed among Trump supporters for whom its largely pro-Trump content was attitude-consistent. However, this pattern of selective exposure was heavily concentrated among a small subset of people - almost six in ten visits to fake news websites came from the $10 \%$ of Americans with the most conservative information diets who were responsible for approximately six in 10 visits to fake news websites during this period. Even in that group, however, fake news made up less than $8 \%$ of their total news 'diet'.

Moreover, the reach of fake news declines dramatically in the period before the 2018 midterm elections (see Guess at al. 2020b). In fall 2018, only 7\% of the public read an article from a fake news site. The only thing that remains constant if we compare the 2016 and 2018 campaigns is related to who does consume fake news. As in fall 2016, fake news consumption in fall 2018 is disproportionately concentrated among the $10 \%$ of Americans with the most conservative news diets.

Summing up, the above reviewed articles arrive at the same conclusion, which can be summarised in two main points. First, the prevalence of fake news on social media seems to be overstated, which would suggest that it is unlikely to cause massive changes in public opinion that many commentators have feared. Second, the results suggest that fake news sources seem to have been a niche interest. In other words, their impact on political discourse might be limited by the same mechanism that helps their posts find traction and spread: the algorithms and filter bubbles that ensure people see political content they were already inclined to agree with. The citizens most likely to interact with Russian trolls or to consume fake news were those the least likely to be influenced by them - because of their more entrenched political views.

\section{Fake news and voting behaviour}

Compared to studies focussing on fake news spread and consumption, the studies linking fake news exposure with voting are far fewer. Usually, the discussion brings forward an indirect evidence rather than a direct one. With respect to former studies, for example, Nyhan (2019) illustrates how there remains no evidence that fake news changed the result of the 2016 election. The reason is that any such claim must take into account not just the reach of fake news, but also the proportion of those exposed to it whose behaviour could be changed. As noted above, approximately six in 10 visits to fake news websites came from the $10 \%$ of Americans with the most conservative news diets - a group that was already especially likely to vote for Donald Trump. 
Similarly, Allcott and Gentzkow (2017) stress that even assuming that a fake news article is as persuasive as a TV campaign ad, which is per se a very strong assumption, the effect of fake news exposure was most certainly not enough to be decisive to the 2016 election outcome given the total amount of consumption of fake news in that election (and, once again, the specific type of users that most heavily consumed such news).

More indirect evidence of the scarce impact of fake news consumption on voter decisions, comes from fact-checking literature. Several studies (Nyhan et al. 2019; Swire et al. 2017) based on an experimental framework show that journalistic fact-checks can reduce belief in fake news items. However, supporters of a specific politician appear not to change their attitudes towards him/her after receiving factchecks, suggesting that voters' preferences are not contingent on their perceptions of the factual accuracy of the candidates (being it true or just fake). In other words, factual corrections can achieve the limited objective of creating a more informed citizenry but struggle to change citizens' minds about whom to support.

One of the few studies focussing on the direct relationship between fake news and voting is the work by Cantarella, Fraccaroli, and Volpe (2019). Interestingly, this study is not based on the US case, but on the Italian one, i.e. it looks at a country where populist parties are strong, and wherein fake news seem to have been largely consumed. ${ }^{4}$ For example, a survey about the 2018 elections showed that the likelihood of sharing so-called fake news was found to be higher for voters of two Italian populist parties (Movimento 5 Stelle and Lega) than for voters of other parties. Second, this is one of the few attempts to study the phenomenon of fake news using a quasi-experimental methodology in order to account for the possible reverse causality issues between voting preferences and exposition to misinformation.

In particular the authors compares two different provinces located in the Trentino Alto-Adige/Südtirol region in Italy. This region, which is located on the border with Austria, is home to a German-speaking linguistic minority and features some degree of language segregation: a parallel German-language media market exists, and effective bilingualism is not particularly widespread (Ebner 2016). In this respect, the authors select the province of Trento and the province of Bolzano. In this latter province, German-speaking citizens are by far the majority. Therefore, we have two different areas next to each other, comparable in terms of economic and demographic conditions, but wherein one province (contrary to the other one) is exposed to a peculiar filter bubble where exposure to fake news concerning Italian politics is limited. In fact, it can be reasonably assumed that fake news disseminators may have little or no incentive to produce fake news especially targeted to the (small) German-speaking population living in Italy. Through that, it becomes possible to exploit the language differences across the two provinces as an exogenous source of variation in exposure to fake news. The authors then gathered municipality-level data on electoral outcomes, demographics, and social media usage from the two provinces and exploited a natural experiment occurring in the region to randomise exposition to fake news. 
The authors' main finding was that the persistence of very similar differences in voting behaviour, especially as far as the support for populist parties is considered, conditioned by linguistic grouping and broadband penetration, indicates that exposure to fake news is entirely dictated by self-selection, meaning that the causal channel between voting and fake news goes in a single direction, with individuals being exposed to fake news because of their prior political presences. A result, once again, consistent with the previous studies that we have discussed.

\section{Conclusion}

How easy is it to change people's votes in an election by disseminating fake news? Much remains to be learnt about the effects of these types of online activities, but people should not assume they have huge effects. This is at least the conclusion of our review. A conclusion that is coherent, inter alia, with our starting expectations grounded in the literature on voting behaviour, psychology, and campaigning.

We have highlighted how voting behaviour cannot be just considered the byproduct of contextual factors, limited to the peculiarities of an electoral campaign, in a specific moment in history. On the contrary, despite the declining impact of the traditional social, cultural, and partisan identities on voting, and the parallel 'self-determination' of voters, the sociographic factors are still relevant in tracing voters' profile and political attitudes, as they constitute the pre-conditions of their contextual decision-making heuristics. Unsurprisingly, then, people tend to consume the news that confirms their pre-established partisan ideas and the impact of campaign advertising (including fake news) on voting seems rather poor. Note that the sociographic factors developed in the 1950 s could be easily extended as a category to include also the current 'online life'.

Accordingly, social media information bubbles can matter independently of the presence of fake news precisely for their being an incarnation of shared narrations within groups of citizens with extended (virtual) social interactions. The ironic thing about all the fake news discussion would be therefore our 'rediscovering' of the important role of a classic issue very well known in the literature on voting behaviour.

This conclusion may sound jarring at a time when people are concerned about the effects of fake news that flooded social media. Observers speculated that these so-called fake news articles swung the election to Trump. Similar suggestions of large persuasion effects have been made about Brexit and the rising of populist parties (in Italy as elsewhere). So why did it happen? Probably for the same reasons that determine the success of the hoaxes: it offers a simplistic explanation (a kind of straw-man concept) for a complex problem and lends itself to be an effective propaganda tool.

None of these findings indicate that fake news isn't a worrisome sign for a democracy. Fake news can have negative effects that extend beyond election outcomes. It can mislead and polarise citizens, undermine trust in the media, ${ }^{5}$ 
and distort the content of public debate. But we need (more) evidence and data, not hype or speculation. Measuring the causal effect of exposition to fake news is indeed far from trivial, as simple correlations do not provide much information on their effect on voting. If people with given political views both vote and consume news accordingly, there is much of the raw correlation that is not causal from fake news to vote.

We end this chapter by highlighting a possible further avenue for the research on fake news and politics. Influencing vote choice is very difficult because likely voters have strong prior beliefs as we discussed. However, experiments demonstrate that persuasive interventions can affect voter turnout (albeit the evidence here is also not so straightforward: see Kalla and Broockman 2018). That is, campaigns can also aim to influence whether voters bother to vote at all (Ansolabehere 2006).

Of course, when assessing the possible relationship between fake news and turnout, it is important to remember that voting is habitual. Effective manipulation, therefore, likely requires targeting occasional rather than regular voters. In social media, however, this type of targeting is possible and, according to some observers, it took place during the 2016 US presidential election. Analysis of the precision of targeting efforts is, therefore, essential to understanding voter turnout effects, in particular to identify both the possible direct effects of fake news consumption on turnout and indirect spillover effects (e.g., word of mouth from recipients to peers). However, studying the relationship between fake news and turnout requires a sophisticated causal approach (Aral and Eckles 2019), rather than an analysis based upon qualitative analyses or anecdotal evidence; something that quite often has been lacking in the public discussion.

\section{Notes}

1 Note, however, that the fears of widespread online 'echo chambers' remain a highly discussed topic. Behavioural data indicates, for example, that only a subset of users - once again characterised by their degree of strong political leaning - have heavily skewed media consumption patterns (Gentzkow and Shapiro 2011; Barberá 2015).

2 This, of course, does not imply that political campaigns are not important. See Kalla and Broockman (2018) for a discussion.

3 We are presenting in this section only works based on the USA case, given the relevance that the 2016 US presidential elections has generated when it comes to the possible role played by fake news. See for example Hall Jamieson (2018).

4 Il Sole 24 Ore (2018) 'Fake news: quando le bugie hanno le gambe lunghe', 4 May 2018, www.infodata.ilsole24ore.com/2018/05/04/fake-news-le-bugie-le-gambe-lunghe/. Note, however, that we should be aware of the results we get when focussing on surveys alone, in particular post-election survey recall. For example, Allcott and Gentzkow (2017) show that $15 \%$ of survey respondents recalled seeing false news stories during the campaign and $8 \%$ recalled both seeing a false story and acknowledging that they believed it. However, a question about exposure to placebo false news stories - untrue but plausible headlines that the authors invented which never actually circulated gives almost the same responses as a question about false news stories that actually did circulate: $14 \%$ of people reported seeing placebo stories and $8 \%$ reported seeing and believing them. This highlights the limitations of recall-based surveys about fake news consumption. 
5 This outcome can also be the by-product of an unintended process. Indeed, it has been shown that when people are exposed to tweets and press articles containing the term 'fake news', their ability to tell real from fraudulent stories decreases (see Van Duyn and Collier 2018).

\section{References}

Allcott, H., M. Gentzkow (2017) 'Social media and fake news in the 2016 election', Joumal of Economic Perspectives 31(2): 211-36.

Ansolabehere, S. (2006) 'The paradox of minimal effects', in: H.E. Brady, R. Johnston (eds), Capturing Campaign Effects, Ann Arbor: University of Michigan Press, 29-44.

Aral, S., D. Eckles (2019) 'Protecting elections from social media manipulation', Science 365(6456): 858-61.

Baila, C.A., B. Guaya, E. Maloneya, A. Combsa, D. S. Hillygusa, F. Merhouta, D. Freelonf, A. Volfovskya (2020) 'Assessing the Russian Internet Research Agency's impact on the political attitudes and behaviors of American Twitter users in late 2017', Proceedings of the National Academy of Sciences 117(1): 243-50.

Bakir, V., A. McStay (2018) 'Fake news and the economy of emotions', Digital Joumalism 6(2): 154-75.

Barberá, P. (2015) 'How social media reduces mass political polarization: Evidence from Germany, Spain, and the US', Mimeo, New York University.

Bellucci P., P. Segatti (eds) (2010) Votare in Italia: 1968-2018, Bologna: Il Mulino.

Bellucci P., P. Whiteley (2005) 'Modelling electoral choice in the twenty-first century: An introduction', Electoral Studies 25: 319-24.

Berinsky, A.J. (2017) 'Measuring public opinion with surveys', Annual Review of Political Science 20: 309-29.

Bessi, A., F. Zollo, M. Del Vicario, M. Puliga, A. Scala, G. Caldarelli (2016) 'Users polarization on Facebook and Youtube', PLoS ONE 11(8): e0159641.

Campbell A., P.E. Converse, W.E. Miller, D. E. Stokes (1960) The American Voter, New York: Wiley.

Cantarella M., N. Fraccaroli, R. Volpe (2019) Does Fake News Affect Voting Behaviour?, DEMB Working Paper Series 146.

Corbetta, P., N. Cavazza (2009) 'Capire il comportamento di voto: dalla debolezza dei fattori sociologici all'insostenibile tesi dell'individualizzazione', Polis 3, https://doi.org/ $10.1424 / 31134$.

Dalton, R.J. (1996) 'Political cleavages, issues and electoral change', in: L. Le Duc, R. G. Niemi, P. Norris (eds), Comparing Democracies: Elections and Voting in Global Perspectives, London -Thousand Oaks: Sage, 319-42.

Dalton R.J., P.M. Wattenberg (eds) (2002) Parties without Partisans: Political Change in Advanced Industrial Democracies, New York: Oxford University Press.

Downs A. (1957) An Economic Theory of Democracy, New York: Harper.

Druckman, J.N. (2004) 'Political preference formation: Competition, deliberation, and the (ir) relevance of framing effects', American Political Science Review 98(4): 671-86.

Druckman, J.N., E. Peterson, R. Slothuus (2013) 'How elite partisan polarization affects public opinion formation', American Political Science Review 107(01): 57-79.

Ebner, C.V. (2016) 'The long way to bilingualism: The peculiar case of multilingual South Tyrol', Intemational Joumal for 21st Century Education 3(2): 25.

Fisher, J., E. Fieldhouse, M.N. Franklin, R. Gibson, M. Cantijoch, C. Wlezien (2017) The Routledge Handbook of Elections, Voting Behaviour and Public Opinion, London: Routledge. 
Gelman, A., G. King (1993) 'Why are American presidential election campaign polls so variable when votes are so predictable?', British Journal of Political Science 23(4): 409-51.

Gentzkow, M., J.M. Shapiro (2011) 'Ideological segregation online and offline', Quarterly Journal of Economics, 126(4): 1799-839.

Grinberg, N., K. Joseph, L. Friedland, B. Swire-Thompson, D. Lazer (2019) 'Fake News on Twitter during the 2016 U.S. presidential election', Science, 363(6425): 374-78.

Guess, A., J. Nagler, J. Tucker (2019) 'Less than you think: Prevalence and predictors of fake news dissemination on Facebook', Science Advances, 5(1): eaau4586.

Guess, A., S. Lach, J. Reifler (2020a) 'Exposure to untrustworthy websites in the 2016 U.S. election', Nature Human Behaviour, forthcoming.

Guess, A., B. Lyons, J. M. Montgomery, B. Nyhan (2020b) 'Fake news, Facebook ads, and misperceptions: Assessing information quality in the 2018 U.S. midterm election campaign', Mimeo, Princeton University.

Gunther, R., J.R. Montero, H.J. Puhle (2007) Democracy, Intermediation, and Voting on Four Continents, Oxford: Oxford University Press.

Hall Jamieson, K. (2018) Cyberwar: How Russian Hackers and Trolls Helped Elect a President: What We Don't, Can't, and Do Know, Oxford: Oxford University Press.

Hart, W., D. Albarracin, A. H. Eagly, I. Brechan, M.J. Lindberg, L. Merrill (2009) 'Feeling validated versus being correct: A meta-analysis of selective exposure to information', Psychological Bulletin 135(4): 555.

Iyengar, S., K.S. Hahn, J. A. Krosnick, J. Walker (2008) 'Selective exposure to campaign communication: The role of anticipated agreement and issue public membership', Journal of Politics 70(1): 186-200.

Iyengar, S., K.S. Hahn (2009) 'Red media, blue media: Evidence of ideological selectivity in media use', Joumal of Communication 59(1): 19-39.

Kalla, J. L., D.E. Broockman (2018) 'The minimal persuasive effects of campaign contact in general elections: Evidence from 49 field experiments', American Political Science Review 112(1): 148-66

Katz, R., P. Mair (1995) 'Changing models of party organisation and party democracy: The emergence of the Cartel party', Party Politics, 1(1): 5-28.

Katz, R., P. Mair (2009) 'The Cartel party thesis revisited', Perspective on Politics 7(4): 753-66.

Kiesler, C.A. (1971) The Psychology of Commitment, New York: Academic Press.

Lauderdale, B.E. (2016) 'Partisan disagreements arising from rationalization of common information', Political Science Research and Methods 4(3): 477-92.

Lazarsfeld, P., B. Berelson, H. Gaudet (1944) The People's Choice: How the Voter Makes Up His Mind in Presidential Campaign, New York: CUP.

Lazer, D.M.J. et al. (2018) 'The science of fake news', Science 359(6380): 1094-96.

Nyhan, B. (2018) 'Fake news and bots may be worrisome, but their political power is overblown', The New York Times, 13 February 2018.

Nyhan, B. (2019) 'Why fears of fake news Are overhyped', Medium, 4 February 2019, https://gen.medium.com/why-fears-of-fake-news-are-overhyped-2ed9ca0a52c9.

Nyhan, B., E. Porterz, J. Reifler, T.J. Wood (2019) 'Taking fact-checks literally but not seriously? The effects of journalistic fact-checking on factual beliefs and candidate favorability', Political Behavior 42(3): 939-60.

Parkinson, H.J. (2016) 'Click and elect: How fake news helped Donald Trump win a real election', The Guardian, 14 November 2016.

Pennycook, G., D.G. Rand (2019) 'Lazy, not biased: Susceptibility to partisan fake news is better explained by lack of reasoning than by motivated reasoning', Cognition 188: $39-50$. 
Rampersad, G., A. Turki (2020) 'Fake news: Acceptance by demographics and culture on social media', Joumal of Information Technology \& Politics 17(1): 1-11.

Read, M. (2016) 'Donald Trump won because of Facebook', New York Magazine, 9 November 2016.

Rokkan, S. (1970) Citizens, Elections, Parties: Approaches to the Comparative Study of the Processes of Development, New York: David McKay.

Sinan, A., D. Eckles (2019) 'Protecting elections from social media manipulation', Science 365: 6456 .

Stroud, N.J. (2008) 'Media use and political predispositions: Revisiting the concept of selective exposure', Political Behavior 30(3): 341-66.

Sunstein, C. (2001) Echo Chambers: Bush Vs. Gore, Impeachment, and Beyond, Princeton, NJ: Princeton University Press.

Swire, B., A.J. Berinsky, S. Lewandowsky, U.K.H. Ecke (2017) 'Processing political misinformation: Comprehending the Trump phenomenon', Royal Society Open Science 4: 160802.

Törnberg, P. (2018) 'Echo chambers and viral misinformation: Modeling fake news as complex contagion', PLOS ONE 13(9): e0203958.

Van Duyn, E., J. Collier (2018) 'Priming and fake news: The effects of elite discourse on evaluations of news media', Mass Communication and Society 22: 29-48.

Vosoughi, S., R. Deb, A. Sinan (2018) 'The spread of true and false news online', Science 359(6380): 1146-51.

Vosoughi, S., D. Roy, S. Aral (2018) 'The spread of true and false news online', Science 359: $1146-51$.

Ward, S.J., R.K. Gibson (2009) 'European political organizations and the Internet: Mobilization, participation, and change', in: A. Chadwick, P. N. Howard (eds), The Routledge Handbook of Internet Politics, London: Routledge, 25-39.

Zaller, J.R. (1992) The Nature and Origins of Mass Opinion, New York: Cambridge University Press. 